\title{
Correspondence
}

\section{Sputum elasticity: a frog in the throat?}

Sir,- It is very useful to draw the attention of chest physicians to the important role of the elasticity of bronchial secretions and in particular to stress the fact that in clinical practice abuse of and overdosage with mucolytic agents can result in an over-thinning of the secretions, which can lead to a reduction in mucociliary clearance.

King et al (1974) were the first authors to show that elasticity was a specific requirement for mucociliary transport function in the frog palate system. The technique of the excised frog palate is a routine method in our laboratory. We have in fact observed (Puchelle et $a l, 1976)$ that bronchitic sputa, initially characterised by optimal values for clearance, were transported at a slower rate after the in-vitro action of mucolytic reducing agents such as $\mathrm{N}$-acetylcysteine. We had therefore suggested that these mucolytic drugs should not be used in patients with low elastic secretions, particularly in advanced stages of chronic bronchitis, where an appreciable decrease in glandular synthesis of secretory proteins is generally associated with a decrease in the viscoelastic properties of bronchial secretions (Sadoul et al, 1978). In patients with advanced chronic bronchitis the use of drugs acting on mucus secretion instead of true mucolytic agents, would seem more justified. Among them, S-carboxymethyl-cysteine (a derivative of cysteine in which the sulphydryl groups are blocked by a carboxylic acid residue) is a mucoregulating agent which does not possess any in-vitro mucolytic activity. This drug seems to be able to exert a restructuring action on nonpurulent bronchial secretions and to enhance their $\vec{\circ}$ viscoelastic properties (Puchelle et al, 1978).

The conclusion we reach is that the drugs modifying $\overrightarrow{\vec{\omega}}$ bronchial secretions should not, at the present time, $\omega$ be administered with the sole purpose of fluidifying sputum, but should rather be directed towards a $\times$ normalisation of the viscoelastic properties of bron- $\stackrel{\omega}{+}$ chial secretions.

EDITH PUCHELLE N PAUL SADOUL

Unité de Physiopathologie Respiratoire, 윽 Inserm $U$ 14, 二 Physio-Pathologie Respiratoire, $>$ Case Officielle no 10, 54500 Vandoeuvre Annexe 2, France

\section{References}

King, M, Gilboa, A, Meyer, F A, and Silberberg, A (1974). On the transport of mucus and its rheologic $\bar{O}$ simulants in ciliated systems. American Review of $\stackrel{\circ}{\circ}$ Respiratory Disease, 110, 740-745.

Puchelle, E, Aug, F, Polu, J M (1978). Effect of the mucoregulator S-Carboxy-methyl-cysteine in patients with chronic bronchitis. European Journal of Clinical Pharmacology. To be published.

Sadoul, P, Puchelle, E, Girard, F (1978). Criteria for evaluating mucus functions and their disorders in 1 chronic bronchitis. In Respiratory tract mucus Ciba Foundation Symposium no 54, 277-295. Elsevir, Amsterdam. 